\title{
COMPROMISO Y PRECARIEDAD EN CLARICE LISPECTOR
}

\author{
Constanza Penacini ${ }^{1}$
}

\section{Resumen}

En diálogo con los debates artísticos y políticos de su tiempo, la propuesta ética y estética de Clarice Lispector hacia el final de su obra parece estar mirando hacia el futuro. A partir de una literatura contemporánea que trabaja con un material poroso y de una escritura que se construye como un mapa afectivo, la apuesta política de la autora se define por una precarización de la literatura.

\section{Palabras clave}

Literatura precaria. Arte contemporáneo. Precariedad. Clarice Lispector. Arte comprometido.

\section{I) Introducción: Una narrativa porosa}

En 1974 se publica $A$ via crucis do corpo, único libro escrito por Clarice Lispector a partir de un encargo. Ya en sus primeras páginas aparecen las marcas de ese origen como estigma, en donde la autora cuenta que alguien ha dicho que sus cuentos son basura y, anticipándose a la condena, se confiesa culpable de escribir por dinero y de escribir cosas vergonzantes. De ese modo deja asentado que renuncia a preservar todo aquello que la sujeta y la mantiene contenida y segura a la institución literaria: un estilo, una obra, un nombre, y la crítica que la consagró:

\footnotetext{
${ }^{1}$ Constanza Penacini es Licenciada en Letras por la Universidad de Buenos Aires y profesora regular de Literatura brasileña en la misma institución. Es becaria CONICET y está culminando su doctorado en Literatura con una tesis sobre Clarice Lispector, también en la FFyL de la UBA. Ha publicado en libros y revistas académicas nacionales e internacionales. Es co-organizadora -junto a Gonzalo Aguilar y Carmen Guiraldes- de "La hora de Clarice", Argentina. Y forma parte de un proyecto de investigación sobre la recepción de Clarice Lispector en Latinoamérica con Mariela Méndez. Ha sido editora de literatura y ensayo durante más de quince años en diferentes editoriales.
} 
Pois é. Sei lá se este livro vai acrescentar alguma coisa à minha obra. Minha obra que se dane. Não sei por que as pessoas dão tanta importância à literatura. E quanto ao meu nome? Que se dane, tenho mais em que pensar. (LISPECTOR, 1998b, 50)

Es el momento de la basura y este libro forma parte de esta última etapa de la obra de la autora que según Ítalo Moriconi significa la superación del arte que podríamos denominar arte moderno o arte letrado, de elite (MORICONI, 2003, p. 720). ¿Pero, qué es lo que comienza luego de ese cierre? En un contexto en el que las artes plásticas vienen experimentando una masiva penetración de materiales que provienen de la vida misma, así surge una literatura contaminada por el mundo real, plagada de desechos y sobrantes, con la irrupción de materiales bajos, géneros populares, temas de dudoso gusto: "los objetos, los cuerpos reales, el sudor, los fluidos, la basura, los sonidos de la cotidianeidad, los restos de otros mundos bidimensionales", enumera Andrea Giunta (2014, p. 10). La de Lispector es una literatura contemporánea, trabaja con un material poroso que ha dejado atrás su lógica autosuficiente y realiza un salto mortal hacia los bordes de esa línea evolutiva que viene trazando la literatura brasileña. Si bien es cierto que "valendo-nos da engenhosa equação concretista, Água viva representa o momento de luxo imprescindível a configuração do lixo enquanto entidade estética" (Moriconi, 2003, p. 720), Lispector no repite el defecto fundante de los concretos en su fase participante: la fe en el Progreso. Aquel, que según Heloísa Buarque de Hollanda, los llevó a un resultado trunco, por "limpio, eficiente, prolijo" (2000, p. 179).

Este camino comienza en A paixão segundo G.H., que es una profunda reflexión sobre el abandono de la seguridad que da la belleza y la humanidad entendida como un sistema de sujeciones que nos alejan de lo vivo que nos rodea. Allí, la narradora se pregunta: "Terei enfim perdido todo um sistema de bom-gosto? [...] Por enquanto o primeiro prazer tímido estou tendo é o de constatar que perdi o medo do feio. E essa perda é de uma tal bondade. É uma doçura.” (LISPECTOR, 1998a, pp. 20-21). Toda una declaración de principios que logrará materializar en sus últimos libros.

Pero Clarice había sido criticada antes por hacer una literatura "introspectiva", "apolítica", que no se comprometía con los problemas sociales de su tiempo. Aquello que se 
consideraba literatura política, debe pensarse aquí en contexto. Como explica Heloísa Buarque de Hollanda (2000, p. 159):

Por su parte, la producción cultural, ampliamente controlada por la izquierda, estará en ese período pre y post 64 marcada por los temas del debate político. Tanto en el ámbito de la producción con características populistas como en relación con las vanguardias, los temas de la modernización, de la democratización, el nacionalismo y la 'fe en el pueblo' estarán en el centro de las discusiones, dando forma y delineando la necesidad de un arte participante, forjando el mito del alcance revolucionario de la palabra poética.

Incorporar la cuestión social a su modo de composición y responder a las demandas era algo que la preocupaba. Y ante las presiones, se defendía ante el juicio de un medio intelectual brasileño que manejaba una concepción del compromiso muy alejado del suyo:

Na verdade, sinto-me engajada. Tudo o que escrevo está ligado, pelo menos dentro de mim, à realidade em que vivemos. É possível que este meu lado ainda se fortifique mais algum dia. Ou não? Não sei de nada. Nem sei se escreverei mais. É possível que não. (LISPECTOR, 1984, p. 49)

Recién algunos años más tarde, con la lectura de Hélène Cixous, y una concepción feminista de lo político asociado a lo privado, modificaría drásticamente la forma de entender la escritura clariceana. Por eso, mirar de frente a una cucaracha y comer su materia blancuzca es el desenlace de lo que comienza con la inmersión al cuarto de la empleada doméstica, que pone a la burguesa narradora de cara a las desigualdades de clase que siempre prefirió ignorar. Es el primer paso hacia la incorporación de lo abyecto, a la metamorfosis. En cualquier caso, Clarice se preocupaba por no quedar del lado conservador, aunque el intento por alinearse al "realismo novo" estaba en las antípodas del proceso intuitivo de composición de la escritora. (ARÊAS, 2005, p. 43)

Las respuestas éticas y estéticas llegaron luego de esa ardua búsqueda. A partir de $A$ via crucis do corpo logra desmarcarse tanto de la opción populista como de la vanguardista. Sin dejar de estar atenta, por un lado, a los debates sobre arte y política; y por otro, a la discusión en torno a la relación del arte con la cultura popular y los mass media que trajeron las vanguardias en el mundo:

Ou vanguarda seria a nova forma, usada para rebentar a visão estratificada e forçar, pela arrebentação, a visão de uma realidade outra -ou, em suma, da realidade? Isso já estava melhor [...] E essa expressão "forma-fundo" 
sempre me desagradou vitalmente - assim como me incomoda a divisão "corpo-alma", "matéria-energia", etc. [...] Um "tema", sim, pode préexistir, e dele se pode falar antes, durante e depois da coisa propriamente dita; mas fundo-forma é a coisa propriamente dita, e do fundo-forma só se sabe do ler, ver, ouvir, experimentar. (LISPECTOR, 1971, p. 121)

Algunos años antes, escribía para una conferencia que dio en la Universidad de Texas justamente sobre literatura y vanguardia en Brasil. La reflexión la llevaba a dejar de lado el término vanguardia para quedarse con aquello que consideraba propio de cualquier arte verdadero: la experimentación. Y en esta línea, como los movimientos de vanguardia, también ella se propone revertir el carácter aurático del arte. Como el Pop Art y el Tropicalismo, a partir de los setentas Lispector lleva adelante esta tarea con su propia literatura y con su figura autoral. La contracara de lo aurático no será, sin embargo, lo mundano del mercado ni el desecho en tanto afuera complementario: Clarice irá hacia el sustrato vital. Para ello,

despoja a la literatura de sus armas de persuasión más flagrantes, renuncia a las organizaciones genéricas y afloja la estructura hasta el borde de lo amorfo para que en la escritura trasunte algo -la vida conociéndose a sí misma- que siempre parece quedar oculto bajo el empaque del artificio. (COHEN, 2003, pp. 49-50)

Vale decir, que lleva adelante una operación precarización literaria.

Esos procedimientos encuentran su concreción en $A$ via crucis do corpo, un libro formalmente heterogéneo, desequilibrado y desparejo, en relación con sus primeros libros de cuentos. Allí, lo residual no se limita apenas a lo temático o procedimental, de hecho, en estos textos forma y tema son indiscernibles, tal como la autora reflexionara años atrás. Se trata de una experimentación indolente, que no busca ningún tipo de eficacia y que se interrumpe insistentemente por momentos de desesperación, en los que una narradora inestable registra los tiempos muertos de la vida que suceden mientras acontece la escritura. El resultado son textos erráticos, poco armónicos, que en muchos casos concluyen abruptamente con desdén e impaciencia. Así es que de las trece historias que resultan del encargo, tres son crónicas acerca de la escritura del libro. A via crucis do corpo explicita sus propias condiciones de producción económicas, creativas y afectivas. Valiéndose de recursos de diferentes géneros -la autobiografía, el fantástico, el proverbio, la fábula, y otros- ${ }^{2}$ resulta un artefacto que dice,

\footnotetext{
${ }^{2}$ Para un análisis más minucioso, ver Com a ponta dos dedos, de Vilma Arêas (2005).
} 
se dice, mira, se mira, y se deconstruye a sí mismo en el mismo acto de composición. De ese modo, se anticipaba a la recepción crítica, dando explicaciones y sometiéndose a juicios de los que, finalmente, se absolvía. ${ }^{3}$

Es en esta narrativa exterior y explícita, "en donde se desarrollan las negociaciones fronterizas entre lo excluido y lo admitido, entre el producto y el residuo" -siguiendo el concepto de lo exformal que define Nicolás Bourriaud (2015, p. 11)-, parte de la crítica y los lectores encontraron allí un basural.

\section{II) Brillante estrella de cine}

Que não esperem, então, estrelas no que segue: nada cintilará, trata-se de matéria opaca e por sua própria natureza desprezível por todos. (LISPECTOR, 1998c, p. 16)

En el trabajo con los géneros masivos y la cultura popular, tanto como en la creación de una voz masculina para hablar del universo femenino, A hora da estrela establece un diálogo con su tiempo y con los debates de su tiempo. Justamente, ese narrador hombre -que reaparece en Um sopro de vida: pulsações - da legitimidad al relato y de esa forma expone paródicamente las absurdas circunstancias de las que el Pop Art fue un caso paradigmático. Como plantea Graciela Speranza, el Pop Art fue llevado adelante por un grupo mayormente hombres que ingresaron al universo femenino para tomar de allí su imaginería -aparatos domésticos, mercancías de supermercado, historietas sentimentales, memorabilia cinematográfica-, y se convirtió en el arte más popular en la historia del arte norteamericano. Pero, "si los artistas pop hubiesen sido mujeres -postula incisivamente-, el movimiento nunca habría salido de la cocina". (SPERANZA, 2000, pp. 92-93)

También puede observarse ese diálogo, en el uso de ciertos procedimientos y reflexiones, tomados tanto de la literatura social -solemne y comprometida-, como de estéticas vanguardistas, inclusive con una reivindicación irónica del kitch. El personaje de Macabea parece salir del repertorio de la literatura social casi como de un molde o, dicho de otro modo, de una representación previa. Y en ese sentido, la construcción podría asimilarse

\footnotetext{
3 “El año anterior había escrito un libro inclasificable (Água viva) y ahora se presentaba con unos relatos llenos de interrupciones y digresiones, obsesionados con la vida sexual de sus personajes y escritos en un estilo taquigráficos y sin ornamentos. Mientras Água viva tenía el aura de lo experimental, los cuentos de El via crucis del cuerpo podían parecer deshilachados y poco elaborados si se los comparaba con Lazos de familia o Felicidad clandestina." (AGUILLAR, 2012, p. 10)
} 
a los términos del Por Art. En la medida que, compuesta a partir de tres o cuatro rasgos genéricos, apenas esbozada, cumple la función de remitir rápidamente a una nordestina perdida en la ciudad, cualquier otra Lindonéia ${ }^{4}$. Sin embargo, la "figurita repetida" de Macabea no informa meramente sobre una información preexistente, sobre un símbolo. Y allí es donde deja atrás el recurso pop, porque algo va más allá de su falta de atributos y lo desborda. $^{5}$

En La hora de la estrella, además, la industria y la alienación cultural quedan neutralizadas por el hambre. El kitch -el de Hollywood, el de la publicidad, el del plástico como lujo- irrumpe aquí como una forma de señalar la marginalidad de Macabea. O mejor, señala una imposibilidad: en esta realidad no hay acceso, siquiera, al mal gusto. Para los ojos de la nordestina: "Lá tudo era de luxo. Matéria plástica amarela nas poltronas e sofás. E até flores de plástico. Plástico era o máximo. Estava boquiaberta.” (Lispector, 1998c, p. 75). Donde Manuel Puig -valiéndose de procedimientos pop- hubiera hecho una escena barrial con una muchacha cualquiera untándose crema hidratante frente al espejo y emulando una publicidad de revista, Clarice pone a Macabea imaginando que se la comería si pudiera acceder a ella. De su femineidad moldeada por la cultura de masas solo quedan unos rasgos mínimos en su fantasía, que se desvanecen con el hambre, y solo se realizan -irónicamenteen la hora de la muerte:

Assim como ninguém lhe ensinaria um dia a morrer: na certa morreria um dia como se antes tivesse estudado de cor a representação do papel de estrela. Pois na hora da morte a pessoa se torna brilhante estrela de cinema, é o instante de glória de cada um e é como no canto coral se ouvem agudos sibilantes. (ibid. p. 29)

Los pocos rasgos que la delinean, por lo tanto, no hacen de ella un ser particular, en la medida que su subjetividad no llega nunca a realizarse. ¿Cuál es la particularidad de Macabea si no tiene atributos y es intercambiable por cualquier otra retirante nordestina? La subjetividad de Macabea aparece encarnada. Es decir, que las marcas deben buscarse en su

\footnotetext{
${ }^{4}$ Nos referimos a A bela Lindonéia (a Gioconda do subúrbio) (1966), de Rubens Gerchman, que fue retomada por los Tropicalistas a partir de una canción de Caetano Veloso.

${ }^{5}$ Dice Oscar Masotta en El Pop Art: "Crítica a todo realismo, entonces: en Lichtenstein, en Indiana, en Warhol, no se trata ya de 'informar' sobre la realidad, y menos se trata de reproducirla. Se trata en cambio de informar sobre una información preexistente, o si se quiere, de representar lo representado. Lo que está 'fuera' de la pintura, en esa perspectiva, era ya pintura; lo que preexistía a la imagen a la imagen plástica era ya imagen plástica.” (MASOTTA, 1967, p. 15)
} 
cuerpo marcado por su inscripción en el mundo. Lo que puede el cuerpo de Macabea no depende individualmente de ella, sino de su contexto social, cultural y afectivo. En ese sentido, ¿cómo podría Rodrigo S.M. evitar su muerte? Si la salva de alguna forma es reconociendo en ella su potencia vital.

Para ser "uma cara só de carne" el personaje de Aurélia Nascimento se vacía de maquillaje, pestañas postizas, lentes de contacto, de rasgos y huesos. ${ }^{6}$ Pero la protagonista de A hora da estrela, dos años más tarde, ya no puede ocultarse detrás del maquillaje. Aunque se pinte los labios o las uñas siempre se ve la mugre, la fealdad, la falta de salud y la pobreza. Macabea está a la intemperie, expuesta como la herida demasiado grande del mendigo bestial de "A bela e a fera"". Es la herida, "grito puro e sem pedir esmola" (LISPECTOR, 1998c, p. 23). Y debajo de ese maquillaje barato y mal colocado nunca termina de aparecer "um rosto humano, triste, delicado" (LISPECTOR, 1998a, p. 44), como sucede con Aurélia. El rostro de Macabea nunca termina de humanizarse y allí reside su originalidad y su fuerza.

La propuesta de Lispector parece estar mirando hacia el futuro, por eso, hay también distancia con su tiempo, y allí es donde reside su anacronismo, su inactualidad. (AGAMBEN, 2011, pp. 17-29)

\section{III) El grito lanzado al futuro}

-Você jura que a literatura não importa? -Juro, respondi com a segurança que vem de íntima veracidade. $\mathrm{E}$ acrescentei: qualquer gato, qualquer cachorro vale mais do que a literatura. (LISPECTOR, 1998a, p. 37)

Entre 1974 y 1976 aparece un desplazamiento muy significativo entre dos personajes de diferentes textos de la autora que pueden leerse como dobles invertidos. Hélène Cixous alguna vez escribió sobre ella: "Si Kafka fuera una mujer. Si Rilke fuera una brasileña judía nacida en Ucrania" (CIXOUS, 1995, p. 157). Una fórmula equivalente podría pensarse para estos personajes: si Miss Algrave fuera brasileña y migrante nordestina... sería Macabea.

\footnotetext{
${ }^{6}$ Del cuento "Ele me bebeu”, en A via crucis do corpo. (LISPECTOR, 1998a, p. 43)

${ }^{7} \mathrm{Me}$ refiero al cuento "A bela e a fera ou A ferida grande demais" recopilado después de la muerte de la autora bajo el mismo título, y que pareciera haber sido escrito en el último período de vida de la autora.
} 
Esta última, que se ha convertido en uno de los objetos más productivos para la crítica clariceana, se desprende -como de un espejo deformado- de la rubia y bella regordeta inglesa, de piel "tão clara e fina que parecia uma seda branca” (LISPECTOR, 1998a, p. 14).

Ambas son mujeres, solteras, vírgenes y pudorosas: "Trata-se de uma moça que nunca se viu nua porque tinha vergonha" (LISPECTOR, 1998c, p. 22). "Nunca havia jantado ou almoçado num restaurante. Era de pé mesmo no botequim da esquina. Tinha uma vaga ideia que mulher que entra em restaurante é francesa e desfrutável.” (ibid. pp. 39-40)

Pero mientras Miss Ruth Algrave es un personaje con nombre y apellido, ascendencia irlandesa, educación y valores religiosos, Macabea es una migrante del nordeste brasileño, huérfana, pobre, sin linaje, tradición ni educación. Ambas son mujeres jóvenes y trabajadoras asalariadas. Ambas, dactilógrafas en una gran ciudad.

Miss Algrave vive en Londres y no le sobra el dinero pero lleva una vida digna. Con un jefe que la trata con respeto y admiración, es una "datilógrafa perfeita", que escribe sin errores y tiene potencial para ser escritora. Es una ciudadana honrada que firma cartas de lectores. Siempre indignada por la inmoralidad ajena, pero nunca indigna. No come carne ni se baña desnuda porque los considera pecado, y está orgullosa de su cuerpo.

Si en el cuento de $A$ via crucis do corpo Miss Algrave tiene un empleo que le da una identidad y una posición, en A hora da estrela el trabajo ya no dignifica. Macabea es una migrante que tiene un empleo, pero su sueldo no cubre siquiera sus necesidades más básicas. Es casi una marginal. Está en el límite porque no tiene nada que vender: es semianalfabeta, sucia, enferma, fea, infértil y tonta. Apenas está en condiciones de ofrecer sus deficientes servicios como dactilógrafa y no tiene ninguna estabilidad, dado que su jefe está a punto de echarla ante cualquier error.

Entre un texto y otro hay dos años, y dos mundos -Latinoamérica y Europa- de diferencia. Lispector logra advertir como pocos el germen de lo que será el estado de situación global en las siguientes décadas de neoliberalismo y creciente control biopolítico de los poderes estatales sobre los cuerpos.

Dos paradigmas se ponen en funcionamiento. En el cuento, el hecho de ser trabajadora, inscribe al personaje en una constelación de sentidos y derechos, propia de los estados de bienestar; en la novela, el personaje-trabajador/a pertenece ya al conjunto de migrantes empujados por fuera de toda legalidad y protección estatal. "En ese mecanismo de 
expulsión de la polis es el inmigrante clandestino el que reemplazó al proletariado" -plantea Bourriaud- $y$, justamente, en las zonas de exclusión generadas por la energía social "se apiñan en completo desorden el proletariado, los explotados, la cultura popular, lo inmundo y lo inmoral: el conjunto subvaluado de todo lo que no se podría ver" (BOURRIAUD, 2015, p. 11). Un conjunto que Lispector incauta para construir este basural y lo expone, lo hace visible y lo deja activo, porque sigue dando claves para pensar el presente.

Macabea es el resto del que la sociedad prescinde y no puede generar empatía en el lector, por lo tanto, la novela impone -valiéndose del grotesco y la ironía- una pregunta fundamental: ¿Es Macabea un ser digno de ser salvado?

A hora da estrela es una interpelación, un enfrentamiento -cara a cara- entre el lector y ese Otro que representa Macabea. Ya en la dedicatoria de la autora, se anuncia: "Esta história acontece em estado de emergência absoluta e de calamidade pública" (LISPECTOR, 1998c, p. 10). Ética y política están en el centro de la escena. Así es como Clarice se distingue brusca y críticamente de la tradición de la literatura social y el naturalismo brasileños de la década del 30, que resurgió en los 60. Sin pedagogías, artilugios ni falsas compensaciones: "Trata-se de um livro inacabado porque lhe falta resposta. Resposta esta que espero que alguém no mundo ma dê. Vós?" (ibid, p. 10). La operación que Lispector lleva adelante con una eficacia asombrosa es una imposición extrema de lo que es éticamente obligatorio: el Otro hace su demanda y pide que se asuma la responsabilidad.

Es el personaje del narrador quien primero se siente interpelado frente al "sentimento de perdição" del rostro de esa nordestina que atrapó al vuelo. Se sabe, el rostro nos pone frente a la extrema precariedad del otro y de la comprensión de esa precariedad resulta tanto la tentación, como la prohibición de matar. De ahí que este escritor oscile entre las ganas de matarla y una necesidad de salvarla que lo llevan a preguntarse. Y, entonces, una escena fundamental se repite entre el cuento y la novela con distinta fortuna. Mientras las dactilógrafas están cruzando la calle -una de Londres, otra de Río-, aparece un automóvil a toda velocidad. Una de las dactilógrafas se salva y, a partir del accidente fallido logra desarrollar todas sus potencialidades: se convierte en un sujeto pleno que renuncia a su trabajo para prostituirse por puro placer: un cuerpo que goza, del sexo, de la comida, de la exhibición. La otra -la latinoamericana- es embestida y muere, anónima y casta. 
Lispector sabe que existe el derecho al grito, que "el rostro parece ser una especie de sonido, el sonido de un lenguaje vaciado de sentido, el sustrato de vocalización sonora que precede y limita la transmisión de cualquier rasgo semántico” (BUTLER, 2006, p. 169). Algunos humanos dan por supuesta su humanidad, mientras que otros luchan por acceder a ella. Por eso grita.

\title{
IV) Conclusión: Una literatura precaria
}

\author{
Vanguarda seria, pois, em última análise, um dos instrumentos de \\ conhecimento, um instrumento avançado de pesquisa. Esse modo de \\ experimentação partiria de renovações formais que levariam ao reexame de \\ conceitos, mesmo de conceitos não formulados.
}

(LISPECTOR, 1971, p. 15)

Detrás de todas las sujeciones y mediaciones (clase, gusto, industria cultural) late lo orgánico de la vida. No es una lectura de clase ni cultural, ni biológica. O, al menos, no es solo eso. En un largo camino que transita Clarice, que comienza en A paixão segundo G.H., se desata en Água viva y se materializa definitivamente en los textos siguientes, la autora realiza un insight hacia lo molecular en donde todos somos todo y todo somos todos. ¿De qué manera logra igualar a Macabea con otros? Yendo al origen de lo biológico, de la vida. Esa es la única equidad que al artista le es posible dar. No hay justicia poética, hay apenas un sustrato vital indiferenciado. "Pero el infierno de lo indiferenciado, por más horror que cause al ser humano, es la libertad más amplia: porque en él lo inconmensurable y la vida (sin conceptos, sin recompensa, sin juicio) no sacrifica la actualidad al ansia de lo porvenir", escribe Marcelo Cohen (2003, p. 48).

Clarice, entonces, propone una escritura del cuerpo y un cuerpo de la escritura. Un cuerpo concebido desde su potencia y su vulnerabilidad, según el legado de Spinoza. Sumergida en un lenguaje desamparado e impersonal como la nordestina que nombra, porque esa trascendencia material supone un descentramiento subjetivo: “A ação desta história terá como resultado minha transfiguração em outrem e minha materialização enfim em objeto". (Lispector, 1998c, p. 29)

En la profusión de fotografías que circulan de Clarice Lispector, aparece hermosa, sensual y misteriosa: en un tono que la emparenta con las imágenes del star system 
cinematográfico, de poses y gestos estudiados, y que definitivamente ha surtido -y surteefecto sobre su público. Ya en 1976 los periodistas argentinos decían -cuando Lispector estuvo de visita en Buenos Aires- que parecía una estrella de cine. En su literatura, por el contrario, se desmonta, también como Aurélia Nascimento, para quedar expuesta como Macabea. Una búsqueda en donde se desprende de sus atributos buscando "ser bio" (y no autobiográfica), según confiesa en Água viva.

El resultado, lejos de ser colorido, alegre, descarado o melodramático, como en Puig o en los Tropicalistas, es sin brillo, con gusto a poco ${ }^{8}$. Lispector propone una literatura sin red. Que no es pobre ${ }^{9}$, popular ni masiva: es una literatura precaria. Una precariedad integral, que no distingue forma, tema ni argumento.

En 1974, en la conferencia de Río de Janeiro, Michel Foucault menciona por primera vez el término "biopolítica", que recién definirá en una de sus lecciones de 1976 (ESPÓSITO, 2011, p.46). Este dato de color, que acerca geográficamente al pensador francés con la escritora brasileña, resulta significativo cuando recordamos que en esos mismos años Lispector publica los cuentos reunidos en A via crucis do corpo y su novela A hora da estrela. También en 1976, Julia Kristeva reclama la necesidad de una nueva ética que pueda soportar el pensamiento de la muerte, y que exige la participación de las mujeres:

Nada dice, sin embargo, que sea posible una ética femenina, y Spinoza excluía de ella a las mujeres (junto con los niños y los locos). Ahora bien, si una ética de la modernidad no se confunde ya con la moral; si una ética consiste no en evitar la embarazosa e ineludible problemática de la ley, sino en darle cuerpo, lenguaje y goce, entonces su reformulación exige la participación de las mujeres. De las mujeres portadoras del deseo de reproducción (de estabilidad). De las mujeres disponibles para que nuestra especie parlante, que se sabe mortal, pueda soportar la muerte. De las madres. Pues la ética herética disociada de la moral, la herética, es quizá lo que, en la vida, hace que los lazos, y por lo tanto el pensamiento de la muerte, sean soportables (KRISTEVA, 1976, p. 230).

Una mujer desde Brasil desarrolla una literatura que reconecta vida y pensamiento en sintonía con reflexiones que empiezan a tomar forma. Dado que la simultaneidad es una de

\footnotetext{
8 "O gosto do vivo. Que é um gosto quase nulo.", dirá en A paixão segundo G.H. (LISPECTOR, 1998b, p. 50)

${ }^{9}$ Uso aquí la idea de "pobreza" como se entendió tradicionalmente, vinculada a la desocupación y la marginalidad laboral. Con la precariedad laboral, la pobreza dejó de ser el reverso del trabajo y surgió una nueva figura, la del trabajador pobre.
} 
las características que distinguen al arte contemporáneo del arte moderno, este ya no será evolutivo ni se desarrollará del centro hacia la periferia.

El elemento vitalista en Lispector está presente desde su primera novela. He trabajado en otra oportunidad su escritura como un mapa afectivo, un mapa vivo ${ }^{10}$. Es hacia el final de su obra que logra concretar el compromiso político que su literatura podía asumir sin traicionarse a sí misma. En tanto cuerpo, su escritura debe pensarse, entonces en su condición precaria. En A hora da estrela el vitalismo se combina con una idea de precariedad como ese lugar de vulnerabilidad inicial que iguala cuerpos de distintos géneros y especies; así como de precaridad" ${ }^{11}$, en la medida que "Precarity is the rubric that brings together women, queers, transgender people, the poor, the differently abled, and the stateless" (BUTLER, 2009, p. 13). En la decisión de precarizar la literatura y hacer una escritura de la carne, habita un pensamiento biopolítico. Así es como se materializa la más fuerte apuesta ética y estética de Clarice Lispector.

\section{Referencias}

Agamben, Giorgio. ¿Qué es lo contemporáneo?. In: Desnudez. Buenos Aires: Adriana Hidalgo, 2011.

Aguilar, Gonzalo. Mundo perro, mundo porno, mundo abrigo: El via crucis del cuerpo. In: El via crucis del cuerpo. Buenos Aires: Corregidor, 2012.

Arêas, Vilma. Clarice Lispector. Com a ponta dos dedos. São Paulo: Companhia das Letras, 2005

Bourriaud, Nicolas. La exforma. Buenos Aires: Adriana Hidalgo, 2005.

Buarque de Hollanda, Heloisa. La participación comprometida en el furor de los años sesenta. In: Absurdo Brasil. Polémicas en la cultura brasileña. Buenos Aires: Biblos, 2000.

Butler, Judith. Vidas Precarias. El poder del duelo y la violencia. Buenos Aires: Paidós, 2006.

\footnotetext{
${ }^{10}$ Véase "Clarice Lispector: el cuerpo de la escritura" (Penacini, 2017, p. 285).

${ }^{11}$ Gabriel Giorgi trabaja en profundidad esta lectura de A hora da estrela, en “¿De qué está hecha Macabea? Lispector y lo precario" (Giorgi, 2017, p. 151).
} 
. Marcos de guerra. Las vidas lloradas. Buenos Aires: Paidós, 2010. - Performativity, precariety and sexual politics. In: AIBR. Revista de

Antropología Iberoamericana. Vol. 4, No 3, Set.-Dec. 2009. pp. 1-13. Madrid: Antropólogos Iberoamericanos en Red.

Cixous, Hélène. La risa de la medusa. Ensayos sobre la escritura. Barcelona: Anthropos, 1995.

Cohen, Marcelo. Una comida para Clarice Lispector. In: Realmente fantástico. Buenos Aires, Norma, 2003.

Espósito, Roberto. Bios. Biopolítica y filosofía. Buenos Aires: Amorrortu, 2011.

Giorgi, Gabriel. ¿De qué está hecha Macabea? Lispector y lo precario. In: ¿Por qué Brasil, qué Brasil? Recorridos críticos. La literatura y el arte brasileños desde Argentina" (Roxana Patiño y Mario Cámara, editores). Córdoba: Eduvim, 2017.

Giunta, Andrea. ¿Cuándo empieza el arte contemporáneo? Buenos Aires: FundaciónarteBA, 2014.

Kristeva, Julia. Stabat Mater. In: Historias de amor. Buenos Aires, Siglo XXI: 1976. Lispector, Clarice. Um sopro de vida (pulsações). Rio de Janeiro, Editora Nova Fronteira: 1978. . Sobre o conceito de vanguarda. In: Remate de Males. São Paulo:

Campinas, Vol. 12, 1992, pp. 117-129. Consultado el 20/08/2020. http://repositorio.unicamp.br/bitstream/REPOSIP/118229/1/ppec_8635913-5576-1-PB.pdf . A descoberta do mundo. Rio de Janeiro: Rocco, 1984. . A paixão segundo G.H. Rio de Janeiro: Rocco, 1998a. . A via crucis do corpo. Rio de Janeiro: Rocco, 1998b. . A hora da estrela. Rio de Janeiro: Rocco, 1998c. . Donde se enseñará a ser feliz y otros escritos. Siruela: Madrid, 2009. . La hora de la estrella. Buenos Aires: Corregidor, 2011. . El vía crucis del cuerpo. Buenos Aires: Corregidor, 2012. . La bella y la bestia. Buenos Aires: Corregidor, 2013. Masotta, Oscar. El Pop Art. Buenos Aires: Nuevos esquemas, 1967. 
Moriconi, Ítalo. A Hora da Estrela ou A Hora do Lixo de Clarice Lispector. In: Rocha, João Cezar de Castro (org.). Nenhum Brasil existe: pequena enciclopédia. Rio de Janeiro: Universidade, Opbook 1, UERJ, 2003.

Penacini, Constanza. Clarice Lispector: el cuerpo de la escritura. In: ¿Por qué Brasil, qué Brasil? Recorridos críticos. La literatura y el arte brasileños desde Argentina" . (Patiño, Roxana et. al), Córdoba: Eduvim, 2017.

Speranza, Graciela. Manuel Puig. Después del fin de la literatura. Buenos Aires: Norma, 2000.

\title{
Commitment and precariousness in Clarice Lispector
}

\begin{abstract}
In dialogue with the artistic and political debates of her time, Clarice Lispector's ethical and aesthetic proposal towards the end of her work seems to be looking to the future. Based on a contemporary literature that works with a porous material and a writing that is constructed as an affective map, the author's political commitment is defined by a precariousness of literature.

\section{Keywords}

Precarious literature. Contemporary art. Precariousness. Clarice Lispector. Committed art.
\end{abstract}

\section{Compromisso e precariedade na Clarice Lispector}

\section{Resumo}

Em diálogo com os debates artísticos e políticos de seu tempo, a proposta ética e estética de Clarice Lispector no final de sua obra parece estar voltada para o futuro. A partir de uma literatura contemporânea que trabalha com um material poroso e de uma escrita que se constrói como mapa afetivo, o compromisso político do autor é definido por uma precariedade da literatura.

\section{Palavras-chave}

Literatura precária. Arte contemporânea. Precariedade. Clarice Lispector. Arte comprometida 